\title{
Chronic upper abdominal pain: site and radiation in various structural and functional disorders and the effect of various foods
}

\author{
J Y Kang, H H Tay, R Guan
}

\begin{abstract}
Pain site and radiation and the effect of various foods were studied prospectively in a consecutive series of patients with chronic upper abdominal pain. Patients followed for less than one year were excluded unless peptic ulcer or abdominal malignancy had been diagnosed or laparotomy had been carried out. A total of 632 patients were eligible for the first study and $\mathbf{4 3 1}$ for the second. Gastric ulcer pain was more likely to be left hypochondrial (17\%) compared with pain from duodenal ulcer $(4 \%)$ or from all other conditions (5\%). It was less likely to be epigastric (54\%) compared with duodenal ulcer pain $(75 \%)$. Oesophageal pain was more likely to be both retrosternal and epigastric $(25 \%)$ compared with non-oesophageal pain (2\%). Radiation to the back was more common in peptic ulcer (31\%) and biliary pain (35\%) compared with functional pain (20\%). Pain precipitation by fatty foods was commoner in biliary disease $(40 \%)$ than in duodenal ulcer $(11 \%)$, peptic ulcer $(9 \%)$, or non-ulcer dyspepsia (19\%). Orange, alcohol, and coffee precipitated pain more frequently in duodenal ulcer $(41 \%, 50 \%$, and $43 \%$ respectively) than in biliary disease $(17 \%, 0 \%$, and $14 \%$ respectively). Chilli precipitated pain in one quarter to one half of subjects regardless of diagnosis. Approximately one tenth of all subjects avoided chilli, curry, coffee, and tea because of medical or other advice.
\end{abstract}

Upper abdominal pain can be caused by a large number of structural and functional disorders. While the typical sites of pain caused by different conditions are well known, variations occur. The advent of modern imaging techniques has made a definitive diagnosis possible for most patients. This study aimed to compare the site and radiation of upper abdominal pain caused by different conditions and to investigate the effect of ingestion of individual foods on upper abdominal pain.

Division of

Gastroenterology,

Department of Medicine,

National University

Hospital, Singapore

J Y Kang

H H Tay

R Guan

Correspondence to:

Associate Professor J Y Kang, Division of Gastroenterology, Department of Medicine, National University Hospital, Lower Kent Ridge Road Singapore 0511 .

Accepted for publication 21 October 1991

\section{Methods}

PAIN SITE

All patients presenting to one of us (JYK) with upper abdominal pain between April 1984 and December 1987 were included in the study whether the pain was the only complaint or one of several complaints. The author is a physician, and patients with acute surgical abdomens were seldom seen and not included in the present study. The site of pain was recorded as epigastric, right or left hypochondrium, periumbilical, right or left lumbar, or generalised following the landmarks suggested by French.' The abdomen was divided into nine regions by the intersection of two horizontal and two sagittal planes. The upper horizontal plane was at a level midway between the suprasternal notch and the symphysis pubis. The lower plane was at the upper border of the iliac crests. The sagittal planes were vertical lines drawn through points midway between the pubis and the anterior superior iliac spines. Patients with suprapublic and right and left iliac fossa pains were not included in the present study unless there was concomittant upper abdominal pain. The site of radiation to the back, if present, was recorded as (a) right, left, or central and (b) thoracic or lumbar using the 12 th ribs as landmarks.

\section{EFFECT OF VARIOUS FOODS}

Consecutive patients presenting with upper abdominal pain of at least three months' duration as the only complaint or as one of several complaints between April 1984 and December 1987 were included in the study. The time period of three months was chosen since patients with shorter histories, and thus fewer pain episodes, may not be able to determine the effect of individual food items on their pain.

After a routine history had been obtained, each patient was shown a list of food items chilli, fatty foods, curry, orange, other fruits, cucumber, onions, alcohol, coffee, and tea. He or she was asked whether (1) each food was taken regularly (at least once weekly) without exacerbation of pain, (2) each food item brought on pain. For food items that were deliberately avoided patients were further asked to indicate if the avoidance was because of dislike or because of advice from physicians, friends, or other sources of information, even though the patient did not notice any direct relationship between those items and the onset of pain.

\section{PATIENT EVALUATION}

A full history was taken and physical examination performed. In most cases investigation included blood count, erythrocyte sedimentation rate, liver function tests, and gastroduodenoscopy, although the latter was not repeated if it had recently been performed at another institution. Other endoscopic, radiological (including ultrasonography, computed tomography, and angiography), or other studies were performed if clinically indicated. Generally, abdominal ultrasonography was performed if 
there was severe pain consistent with biliary colonic. Patients with recent change of bowel habits underwent sigmoidoscopy if they were aged below 40 years. Older subjects underwent barium enema examination or colonoscopy.

After initial diagnosis and treatment, patients were followed up either at the outpatient clinic, by telephone interview, or by a postal questionnaire. Enquiry was made as to whether any new diseases had been detected to account for the patients' original abdominal pains. Patients followed up for less than one year after completion of investigations were excluded from the study unless peptic ulcer or abdominal malignancy had been diagnosed or unless laparotomy had been performed, thereby reducing the chances of a wrong diagnosis.

Patients with gastric ulcers underwent routine biopsy and were followed until healing occurred. Oesophagitis was diagnosed by a combination of criteria including clinical and endoscopic findings as well as the acid infusion test. Irritable bowel syndrome was diagnosed by exclusion of structural disease plus the presence of at least two of the following criteria: altered bowel habit, relief of pain by defecation, looser and/or more frequent stools with onset of pain, passage of mucus, abdominal distension, ${ }^{2}$ and reproduction of pain by colonic air insufflation at sigmoidoscopy. ${ }^{3}$ Non-ulcer dyspepsia was defined as pain related to food and/or relieved by antacids in the absence of organic disease and irritable bowel syndrome. Patients with gastric or duodenal erosions or endoscopic gastroduodenitis were considered, for the purposes of this study, to have functional disease since it has not been proved that these cause symptoms. However, patients with duodenal pseudodiverticula or scarring were considered to have duodenal ulcer. Patients with cholelithiasis and/or choledocholithiasis and those with gall bladder carcinoma were grouped together since these diagnoses tended to occur in the same patients.

\section{REPRODUCIBILITY OF DATA COLLECTION}

In order to assess the reproducibility of the assessment of pain site and radiation, consecutive patients were seen again by JYK one to three months after the initial interview and were questioned a second time about pain site and radiation as well as the effect of various foods, without the original records being available. The period of one to three months was chosen since this was not short enough for the questioner to be

TABLE I Patient diagnoses

\begin{tabular}{|c|c|c|c|c|}
\hline & \multicolumn{2}{|l|}{ Study $l^{\star}$} & \multicolumn{2}{|l|}{ Study $2 t$} \\
\hline & $\operatorname{No}(\%)$ & Male:female & $\mathrm{No}(\%)$ & Male:female \\
\hline $\begin{array}{l}\text { Gastric ulcer } \\
\text { Duodenal ulcer } \\
\text { Biliary disease } \\
\text { Non-ulcer dyspepsia } \\
\text { Irritable colon } \\
\text { Miscellaneous } \\
\text { Total }\end{array}$ & $\begin{array}{c}35(6) \\
168(27) \\
43(7) \\
174(27) \\
136(21) \\
76(12) \\
632(100)\end{array}$ & $\begin{array}{c}25: 10 \\
107: 61 \\
25: 18 \\
84: 90 \\
60: 76 \\
40: 36 \\
341: 291\end{array}$ & $\begin{array}{c}18(4) \\
125(29) \\
24(6) \\
130(30) \\
97(23) \\
37(8) \\
431(100)\end{array}$ & $\begin{array}{c}14: 4 \\
82: 43 \\
14: 10 \\
63: 67 \\
39: 58 \\
22: 15 \\
234: 197\end{array}$ \\
\hline
\end{tabular}

$\star$ Pain site and radiation.

tEffect of various foods. influenced by his memory of the initial interview and yet not so long that the pain could have genuinely changed.

\section{STATISTICAL ANALYSIS}

The $\chi^{2}$ test, with Yates's correction where appropriate, was used to compare categorical data. Probability values of $<0.05$ were considered significant.

\section{Results}

\section{ExCLUSIONS (Table I)}

\section{Pain site and radiation}

Over the study period, 856 consecutive patients presented with upper abdominal pain. One hundred and fifty one patients without peptic ulcer or gastrointestinal malignancy and in whom laparotomy had not been performed were lost to follow up within one year of the completion of investigations (four died of unrelated diseases within one year). Data collection or investigations were incomplete in 53 and 10 patients respectively. Three patients had dual diagnoses that made the cause of pain difficult to identify (duodenal ulcer and gall stones (2), duodenal ulcer and oesophagitis (1). In seven patients the initial diagnoses may have been wrong. Two patients with duodenal erosions and no scarring were initially diagnosed as non-ulcer dyspepsia but subsequently developed duodenal ulcer. Two other patients thought to have nonulcer dyspepsia subsequently had gall stones demonstrated. Two patients thought to have non-ulcer dyspepsia and irritable colon respectively had gastric ulcer and acute pancreatitis diagnosed at other institutions, four years and 19 months later. Another patient who initially refused endoscopy and whose barium meal was normal, was found to have gastric ulcer at another institution. The proportion of patients whose original diagnoses could have been wrong was therefore $1 \cdot 1 \%(7 /(632+7))$, or $2 \cdot 2 \%$ $(7 /(310+7))$ if only patients with non-ulcer dyspepsia or irritable colon were considered.

In seven patients new diagnoses were made over the follow up period but the original diagnoses were nonetheless felt to be correct. One patient with non-ulcer dyspepsia subsequently developed oesophagitis: another developed duodenal ulcer and cholelithasis was also diagnosed. In both cases different types of pain occurred with the later problems. One patient with duodenal ulcer and another with chronic pancreatitis subsequently developed features of irritable bowel syndrome also. Another patient with gastric ulcer later developed a duodenal ulcer. One patient presented with features of irritable bowel syndrome and a positive air insufflation test. One year later cholelithiasis was diagnosed at another clinic and cholecystectomy performed. Her pains persisted and she was included in the present analysis. One patient who initially refused gastroscopy had a gastric ulcer diagnosed on barium meal examination. When her symptoms failed to improve endoscopy was performed and a biopsy specimen 
showed gastric carcinoma. She was included in the analysis as a patient with gastric carcinoma.

Eight patients with gall stones or duodenal ulcer scars were nonetheless thought to have other causes of pain. These included five patients with gall stones who were felt to have non-ulcer dyspepsia (3), irritable bowel syndrome (1), and pain from unknown causes(1). One patient with a duodenal ulcer scar and features of irritable colon was thought to have irritable colon. Two with duodenal ulcer scars and gall stones were thought to be suffering from their gall stones.

\section{EFFECT OF VARIOUS FOODS}

Of the 856 patients seen over the study period, 574 reported abdominal pain of at least three months' duration. Twenty two of these were excluded because of incomplete data collection, usually the result of language problems. Other exclusions included: patients without peptic ulcer or malignancy in whom laparotomy was not performed and follow up was less than one year (110) (three died of unrelated diseases), investigation incomplete (6); and wrong diagnoses (5).

\section{PATIENT CHARACTERISTICS}

\section{Pain site and radiation}

Six hundred and thirty two patients were available for analysis. There were 341 men and 291 women. The mean age was 42 years (range 1379 ) and the mean follow up period 36.4 months (range 0-78). The mean lengths of follow up for patients with irritable colon and non-ulcer dyspepsia were 39.2 and 42.4 months respectively. Patient diagnoses are shown in Table I. Miscellaneous diagnoses included: gastric cancer (21), oesophageal disease (8), hepatic disease (5), colonic disease (5), pancreatic disease (6), cardiac disease (4), disseminated carcinoma (1), musculoskeletal (2), renal (1), infectious mononucleosis (1), combined gastric and duodenal ulcer (1), stomal ulcer (1), and cause unknown (20).

Of the five patients with hepatic pain, two had hepatitis, one giant haemangioma, one abscess, and one metastatic disease. Patients with colonic pain included four with colonic carcinoma and one with ischaemic colitis. Of the eight patients with oesophageal pain, five had reflux oesophagitis, one a discrete lower oesophageal ulcer, one achalasia, and one a mid-oesophageal carcinoma.
Of the six patients with pancreatic pain, four had pancreatitis while two had pancreatic cysts.

\section{Effect of various foods}

Four hundred and thirty one patients were available for analysis. There were 234 men and 197 women. Their ages ranged from 13 to 79 years. They were followed up for a mean period of 38 months ranging from 0 to 71 months. Their diagnoses are also shown in Table I. Miscellaneous diagnoses included: gastric cancer (9), oesophageal disease (5), pancreatic disease (4), colonic cancer (2), renal disease (1), hepatic metastases (1), musculoskeletal (1), stomal ulcer (1), cardiac disease (1), and unknown (12). Oesophageal diseases included reflux oesophagitis (4) and oesophageal cancer (1). Pancreatic diseases included pancreatitis (3) and pancreatic cysts (1).

\section{REPRODUCIBILITY OF DATA COLLECTION}

\section{Pain site and radiation}

Repeat histories were taken from 89 consecutive patients on two occasions one to three months apart. Exactly the same sites of pain were recorded on both occasions in 70 instances (79\%). In six instances (7\%) the site reported on the second occasion was adjacent to the site initially recorded. In 13 patients $(14 \%)$ the main site of pain was identical in the two interviews but an extra site was reported on one of the two occasions.

The presence or absence of pain radiating to the back concurred in the two interviews in all 89 cases. In 18 of the 27 cases where pain radiation was reported $(67 \%)$, identical sites were recorded in the two interviews. In seven instances $(26 \%)$, the main site of radiation concurred for the two interviews but an extra site was reported on one of the two occasions. In two instances (7\%), the site reported for the second interview was adjacent to that reported for the first.

\section{Effect of various foods}

Seventy one patients were questioned on two occasions one to three months apart. Since 10 food items were listed, there were 710 responses. The replies at the two interviews as to whether each item caused pain (that is, response $1+2 v 3$ ) was concordant for $643 / 710$ items (91\%). The

TABLE II Site of abdominal pain (no (\%))

\begin{tabular}{|c|c|c|c|c|c|c|c|c|c|c|}
\hline & $G U$ & $D U$ & $G C$ & $B I L$ & $N U D$ & $I B S$ & $E S O$ & $Q$ & $M I S$ & All \\
\hline $\begin{array}{l}\text { No of patients } \\
\text { Epigastrium } \\
\text { Right hypochondrium } \\
\text { Left hypochondrium } \\
\text { Epigastrium + right hypochondrium } \\
\text { Epigastrium + left hypochondrium } \\
\text { Epigastrium + both hypochondria } \\
\text { Epigastrium + retrosternal } \\
\text { Other combinations }\end{array}$ & $\begin{array}{l}35 \\
19(54)^{\star} \\
3(8) \\
6(17) \ddagger \\
0 \\
2(6) \\
2(6) \\
2(6) \\
1(3)\end{array}$ & $\begin{array}{l}168 \\
127(75) \dagger \\
11(6) \\
6(4) \uparrow \\
8(5) \\
6(4) \\
5(3) \\
0 \\
5(3)\end{array}$ & $\begin{array}{l}21 \\
12(57) \\
2(9) \\
3(14) \\
1(5) \\
1(5) \\
0 \\
0 \\
2(10)\end{array}$ & $\begin{array}{l}43 \\
30(70) \\
4(9) \\
1(2) \\
2(5) \\
1(2) \\
2(5) \\
1(2) \\
2(5)\end{array}$ & $\begin{array}{l}174 \\
124(71) \\
12(7) \\
13(8) \\
6(3) \\
3(2) \\
6(3) \\
5(3) \\
5(3)\end{array}$ & $\begin{array}{l}136 \\
91(67) \\
6(4) \\
4(3) \\
4(3) \\
4(3) \\
5(4) \\
2(1) \\
20(15)\end{array}$ & $\begin{array}{l}8 \\
6(75) \\
0 \\
0 \\
0 \\
0 \\
0 \\
2(25)^{\star \star} \\
0\end{array}$ & $\begin{array}{l}20 \\
12(60) \\
3(15) \\
1(5) \\
0 \\
1(5) \\
1(5) \\
1(5) \\
1(5)\end{array}$ & $\begin{array}{l}27 \\
15(57) \\
6(21) \\
0 \\
0 \\
1(4) \\
2(7) \\
1(4) \\
2(7)\end{array}$ & $\begin{array}{l}632 \\
436(69) \\
47(8) \\
34(5) \Uparrow \\
21(3) \\
19(3) \\
23(4) \\
14(2)+\dagger \\
38(6)\end{array}$ \\
\hline
\end{tabular}

$\mathrm{GU}=$ gastric ulcer; $\mathrm{DU}=$ duodenal ulcer; $\mathrm{GC}=$ gastric cancer; $\mathrm{BIL}=$ biliary; $\mathrm{NUD}=$ non-ulcer dyspepsia;

IBS=irritable bowel syndrome; $\mathrm{ESO}=$ esophageal; $\mathrm{Q}=$ cause unknown; $\mathrm{MIS}=$ miscellaneous

$\star v \dagger, \star \star v(\dagger+-\star \star): \mathrm{p}<0 \cdot 02$

$\ddagger v \S, \ddagger v(\uparrow-\ddagger): \mathrm{p}<0 \cdot 01$. 
TABLE III Radiation of abdominal pain to the back (no (\%))

\begin{tabular}{|c|c|c|c|c|c|c|c|c|c|c|}
\hline & $G U$ & $D U$ & $G C$ & $B I L$ & $N U D$ & IBS & ESO & $Q$ & MIS & All \\
\hline No of patients & & 168 & & & 174 & 136 & 8 & 20 & & 632 \\
\hline No radiation & $25(71)$ & $116(69)$ & $15(70)$ & $28(65)$ & $140(80)$ & $107(79)$ & $8(100)$ & $12(60)$ & $20(73)$ & $471(75)$ \\
\hline Radiation to back & $10(29)^{\star}$ & $52(31) \dagger$ & $6(30)$ & $15(35) \ddagger$ & $34(20) \Omega$ & $29(21) 9$ & 0 & $8(40)^{\star \star}$ & $7(27)$ & $161(25)+\dagger$ \\
\hline \multicolumn{11}{|c|}{ 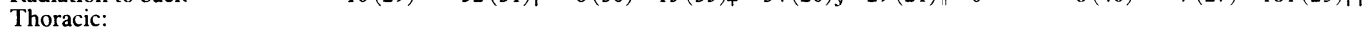 } \\
\hline Central & $2(6)$ & $16(10)$ & $2(10)$ & $6(14)$ & $13(8)$ & $6(5)$ & 0 & $1(5)$ & $1(4)$ & $47(8)$ \\
\hline Right & $1(3)$ & $5(3)$ & & 0 & $2(1)$ & & 0 & 0 & $1(4)$ & $9(1)$ \\
\hline Left & 0 & $4(2)$ & $2(10)$ & 0 & 0 & $1(1)$ & 0 & $2(10)$ & $1(4)$ & $10(2)$ \\
\hline All over & 0 & $3(2)$ & 0 & 0 & $1(1)$ & $2(1)$ & 0 & 0 & 0 & $6(1)$ \\
\hline \multicolumn{11}{|l|}{ Lumbar: } \\
\hline Central & $2(6)$ & $9(5)$ & $1(5)$ & $3(7)$ & $6(3)$ & $4(3)$ & 0 & 0 & $2(7)$ & $27(4)$ \\
\hline Right & 0 & $5(3)$ & 0 & $1(2)$ & $3(2)$ & $1(1)$ & 0 & $3(15)$ & $1(4)$ & $14(2)$ \\
\hline Left & $3(8)$ & $3(2)$ & $1(5)$ & $1(2)$ & $2(1)$ & $2(1)$ & 0 & $1(5)$ & 0 & $13(2)$ \\
\hline All over & $2(6)$ & $5(3)$ & 0 & $2(5)$ & $2(1)$ & $10(7)$ & 0 & $1(5)$ & 0 & $22(3)$ \\
\hline Both thoracic and lumbar & 0 & $2(1)$ & 0 & $2(5)$ & $5(3)$ & $3(2)$ & 0 & 0 & $1(4)$ & $13(2)$ \\
\hline
\end{tabular}

$\mathrm{GU}=$ gastric ulcer; $\mathrm{DU}=$ duodenal ulcer; $\mathrm{GC}=$ gastric cancer; $\mathrm{BIL}=$ biliary; $\mathrm{NUD}=$ non-ulcer dyspepsia;

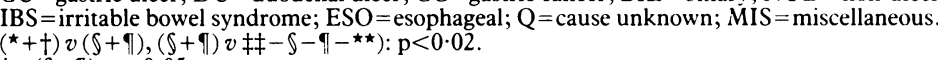

$\ddagger v(\S+\eta): \mathrm{p}<0.05$.

two interviews were concordant for all three responses for $528 / 710$ items (74\%). For the 150 items which were said to be avoided at both interviews the reason for the irregular intake (dislike or advice) concurred in 128 cases $(85 \%)$.

\section{PAIN SITE AND RADIATION IN DIFFERENT} CONDITIONS (Tables II and III)

For all conditions, the epigastrium was the commonest site of pain. Gastric ulcer pain was less likely to be epigastric than that of duodenal ulcer (19 of $35 v 127$ of $168 ; \mathrm{p}<0.02)$. Pain in gastric ulcer was more likely to be felt in the left hypochondrium than pain from duodenal ulcer ( 6 of $35 v 6$ of $168 ; \mathrm{p}<0.01$ ) or from all other conditions ( 6 of $35 v 28$ of $597 ; \mathrm{p}<0.01$ ). Concurrent retrosternal and epigastric pain was more common in oesophageal disorders than in other conditions ( 2 of $8 v 12$ of $624 ; \mathrm{p}<0.02$ ).

Pain radiation to the back occurred in $25 \%$ of cases. It was more common in peptic ulcer and biliary pain than in functional disorders - that is irritable bowel syndrome and non-ulcer dyspepsia ( 62 of $203 v 63$ of $310 ; p<0.02,15$ of $43 v$ 63 of $310 ; p<0.05)$. Pain radiation was also less likely with functional disorders than with structural disorders - that is, all other diagnoses except for pain of unknown cause (63 of $310 v 90$ of $302 ; \mathrm{p}<0.02$ ).

Surprisingly the occurrence of pain radiation to the back in duodenal ulcer was not influenced by whether the ulcer was anterior or posterior. Eighteen of 58 patients $(31 \%)$ with anterior bulbar ulcers reported back pain compared to 11 of 37 patients $(30 \%)$ with posterior wall ulcers. There was no difference even when radiation to the thoracic or lumber spines were separately considered.

TABLE IV Patients avoiding specific foods because of dislike or advice

\begin{tabular}{lcc}
\hline & $\begin{array}{c}\text { Dislike } \\
\text { No(\%) }\end{array}$ & $\begin{array}{c}\text { Advice } \\
\text { No }(\%)\end{array}$ \\
\hline Fatty foods & $43(10)$ & $12(3)$ \\
Chilli & $58(14)$ & $47(11)$ \\
Curry & $60(14)$ & $44(10)$ \\
Orange & $64(15)$ & $28(7)$ \\
Other fruits & $45(10)$ & $14(3)$ \\
Cucumbers & $116(27)$ & $7(2)$ \\
Onions & $108(25)$ & $4(1)$ \\
Alcohol & $338(78)$ & $14(3)$ \\
Coffee & $85(20)$ & $56(13)$ \\
Tea & $110(27)$ & $37(9)$ \\
\hline
\end{tabular}

\section{EFFECT OF VARIOUS FOODS IN DIFFERENT} CONDITIONS

\section{Food avoidance because of dislike or advice}

The proportions of patients who avoided particular foods because of dislike or advice are shown in Table IV. A substantial proportion of subjects avoided particular food items because of dislike. This was particularly true of alcohol, probably for cultural reasons. More than one in 10 of all subjects avoided chillis, curry, and coffee because of advice from friends, physicians, or other sources of information.

\section{Pain precipitation by various foods}

Table V lists the proportions of subjects reporting pain after particular foods, those avoiding particular items from dislike or advice having been excluded. Patients with biliary disease reported precipitation of pain by fatty foods $(40 \%)$ more often than patients with duodenal ulcer $(11 \%, \mathrm{p}<0.005)$, peptic ulcer $(9 \%$, $\mathrm{p}<0.001)$, or non-ulcer dyspepsia $(19 \%$, $\mathrm{p}<0.005)$. The differences between biliary pain and irritable colon (28\%) and between irritable colon and non-ulcer dyspepsia were not significant.

Apart from fatty foods, biliary pain tended to be precipitated by food less often than peptic ulcer or functional pain. Orange brought on duodenal ulcer pain in $41 \%$ of cases compared with $17 \%$ of patients with biliary disease $(p<0.05)$. None of six patients with biliary pain reported exacerbation after alcohol compared with $50 \%$ of duodenal ulcer patients $(p<0.05)$. Similarly, exacerbation of pain by coffee occurred more often with duodenal ulcer $(43 \%)$ than biliary pain $(14 \%, \mathrm{p}<0.05)$.

\section{Discussion}

While the evaluation of chronic upper abdominal pain should follow the traditional sequence of history, physical examination, and special investigations, the medical history is often unhelpful in the diagnostic process. ${ }^{+}$Recent work suggests that the discriminative value of the history can be improved if it is collected and analysed in a structured way with reference to an adequate database. ${ }^{56}$ The typical sites of abdominal pain in various disorders are well described in 
TABLE V Proportions of patients in whom specific foods precipitated pain $(\text { no }(\%))^{1}$

\begin{tabular}{|c|c|c|c|c|c|}
\hline & $D U$ & $G U$ & $B I L$ & $N U D$ & IBS \\
\hline Fatty foods & $12 / 114(11)^{\star}$ & $0 / 17 \dagger$ & $8 / 20(40) \ddagger$ & $21 / 113(19) \S$ & $23 / 82(28)$ \\
\hline Chilli & $39 / 100(39)$ & $4 / 11(36)$ & $4 / 16(25)$ & $45 / 95(47)$ & $35 / 77$ (45) \\
\hline Curry & $39 / 99(39)$ & $5 / 13(38)$ & $4 / 16(25)$ & $47 / 96(49)$ & $35 / 75(47)$ \\
\hline Orange & $41 / 100(41)$ & $4 / 14(29)$ & $3 / 18(17)^{\star \star}$ & $27 / 101(27)$ & $24 / 76(32)$ \\
\hline Other fruits & $16 / 106(15)$ & $4 / 16(25)$ & $0 / 20$ & $8 / 113(7)$ & $3 / 84(4)$ \\
\hline Cucumbers & $3 / 97(3)$ & $1 / 12(8)$ & $0 / 21$ & $4 / 90(4)$ & $0 / 59$ \\
\hline Onions & $4 / 100(4)$ & $0 / 12$ & $0 / 20$ & $6 / 92(7)$ & $0 / 64$ \\
\hline Alcohol & $15 / 30(50) \neq \ddagger$ & $1 / 3(33)$ & $0 / 680$ & $7 / 18$ (39) & $4 / 17(24)$ \\
\hline Coffee & 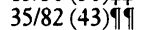 & $3 / 15(20)$ & $2 / 14(14)^{\star \star \star}$ & $32 / 90(36)$ & $26 / 63(41)$ \\
\hline Tea & $21 / 87(24)$ & $2 / 13(15)$ & $2 / 13(15)$ & $21 / 91(23)$ & $10 / 47(21)$ \\
\hline
\end{tabular}

'This table excludes those avoiding the foods because of dislike or advice. Therefore the denominator is different for each food item/diagnosis.

$\mathrm{DU}=$ duodenal ulcer; $\mathrm{GU}=$ gastric ulcer; $\mathrm{BIL}=$ biliary; $\mathrm{NUD}=$ non-ulcer dyspepsia; $\mathrm{IBS}=$ irritable bowel.

${ }^{\star} v \ddagger,\left({ }^{\star}+\dagger\right) v \neq, \neq v \hat{y}: \mathrm{p}<0.005$.

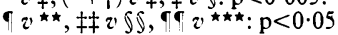

standard textbooks. However, the newer diagnostic methods now available allow greater precision in diagnosis. While several recent studies have addressed the site of pain in individual conditions most were retrospective and few addressed the issue of whether pain site was of help in differentiating between various conditions. We therefore decided to prospectively study the site and radiation of upper abdominal pain in a consecutive series of patients and to determine whether pain site and radiation helped in diagnosis.

Pain localised to the epigastrium is thought to occur more frequently in peptic ulcer than in non-ulcer dyspepsia, and uncommonly in cholelithiasis. ${ }^{7}$ Seventy per cent of patients with peptic ulcer in one series reported epigastric pain. ${ }^{6}$ In another series, $61 \%$ of duodenal ulcer patients reported their pain in the epigastrium and $17 \%$ in the right hypochondrium. ${ }^{8}$ In contrast $60 \%$ and $47 \%$ of patients with gall stones experienced pain in the epigastrium and right hypochondrium respectively. ${ }^{9}$

Our results indicate that the epigastrium is the commonest site of pain in all conditions that cause upper abdominal pain. When not in the epigastrium, gastric ulcer pain occurred more often in the left hypochondrium and less often in the right hyponchondrium. It is of interest that pain sites in gastric cancer were very similar to those in gastric ulcer, although with smaller numbers the differences between gastric cancer and non-gastric ulcer causes of pain were not statistically significant. Oesophageal pain occurred more often retrosternally and in the epigastrium than pain arising from other conditions. However, pain site was in general unhelpful in discriminating between the different causes of chronic upper abdominal pain. In the same way, while pain radiation to the back was more likely in peptic ulcer disease than in functional disorders, the difference was not sufficiently great to be diagnostically useful.

It is known that upper abdominal pain can be precipitated by ingestion of certain foods. For example, Spiro stated that orange juice, coffee, and alcohol often brought on duodenal ulcer pain. ${ }^{10}$ Sherlock stated that the pain of acute cholecystitis can be precipitated by fatty foods." However, the relationship between particular foods and abdominal pain caused by specific disorders has not been well studied.

Talley reported that aggravation of pain by alcohol occurred more commonly in peptic ulcer and non-ulcer dyspepsia than in cholelithiasis.? This is consistent with findings from the present study, although the difference between biliary pain and non-ulcer dyspepsia was not statistically significant. In Earlam's series $62 \%$ and $54 \%$ respectively of duodenal ulcer patients reported that cucumber and onion exacerbated their abdominal pain. ${ }^{8}$ These food items precipitated pain in less than $10 \%$ of our patients. Curry was included in this study because in this part of the world curry contains not only chilli but also coconut, commonly believed to cause dyspepsia. 'Other fruits' was included because we had the impression that pineapples, apples, and pears provoked dyspepsia. Our results indicate that this is not so. As with a previous report, ${ }^{12}$ we found coffee to be a common precipitant of pain in duodenal ulcer, and also non-ulcer dyspepsia. Tea bought on pain in $15-25 \%$ of subjects regardless of aetiology.

Our data support the popular belief that fatty foods precipitate biliary pain," albeit in only $40 \%$. Coffee was less likely to cause biliary pain than pain from duodenal ulcer. ${ }^{12}$ In contrast the frequency of pain precipitation by other foods tended to be similar irrespective of cause. Whether or not pain is precipitated by individual foods is therefore of no discriminant value in the differential diagnosis of chronic upper abdominal pain.

Whether a particular food brings on abdominal pain is to some extent a subjective finding and thus liable to be influenced by preconceptions and popular beliefs. The possibility of bias was minimised in the present study by taking the food history before the actual diagnosis was established.

It is disturbing that a significant proportion of patients avoided specific food items because of advice from physicians, friends, or other sources of information. Since chillis and other foods are not proved to be deleterious, a large number of individuals were being deprived of their enjoyment of these foods through misconceptions at times initiated or encouraged by the medical profession.

We did not attempt to ascertain variability in food preparation and presentation. It is possible that factors such as food temperature, size of meal, and whether fruits are taken whole or in juice form, may affect pain provocation. However, the number of extra variables involved would have made such a study impractical.

We encountered a large number of patients with functional upper abdominal pain who also had features of irritable bowel syndrome. We have arbirtarily considered these patients to have irritable bowel syndrome rather than non-ulcer dyspepsia, ${ }^{13}$ but the distinction is to some extent semantic. Similarly, our definition of non-ulcer dyspepsia as pain related to food means that some of our patients classified under unknown causes of pain would have been labelled as nonulcer dyspepsia by other workers. ${ }^{713}$

A large number of our patients had irritable bowel syndrome. This is consistent with previous findings that balloon distension of the colon frequently produced upper abdominal pain in these patients, ${ }^{1+15}$ 
1 French EB. The alimentary and genito-urinary system. 2nd ed. In: Macleod, J, ed. Clinical Examination. Edinburgh: Livingstone, 1968: 232-74.

2 Manning AP, Thompson WG, Heaton KW, Morris AF Towards positive diagnosis of the irritable bowel. $B M \dot{F}$
1978; $3: 653-4$.

3 Fielding JF. Irritable bowel syndrome: physical signs and investigations. In: Read NW, ed. Irritable bowel syndrome. London: Grune \& Stratton, 1985: 43-52.

4 Anonymous. Data base on dyspepsia. BMF 1978; 1: 1163-4.

5 de Dombal FT. Analysis of foregut symptoms. In: Baron HJH, Moody FG, eds. Foregut. London: Butterworth, 1981: 49-66.

6 Crean GP, Spiegelhalter DJ. Symptoms of peptic ulcer. In: Brooks FP, Cohen S, Soloway RD, eds. Peptic ulcer disease. New York: Churchill Livingston, 1985: 1-15.

7 Talley NJ, McNeil D. Piper DW. Discriminant value of dyspeptic symptoms: a study of the clinical presentation of
221 patients with dyspepsia of unknown cause, peptic ulceration, and cholelithiasis. Gut 1987; 28: 40-6.

8 Earlam R. Computerized questionaire analysis of duodenal ulcer symptoms. Gastroenterologv 1976; 71:31+-7.

9 Gunn A, Keddie N. Some clinical observations on patient with gallstones. Lancet 1972; ii: 239-4.

10 Spiro HM. Clinical gastroenterologi'. 3rd ed. New York: Macmillan, 1983: 319

11 Sherlock S. Diseases of the liver and biliary system. 6th ed. Oxford: Blackwell, 1981: 484 .

12 Eisig JN, Zaterka J, Massuda HK, Bettarello A. Coffee drinking in patients with duodenal ulcer and a control population. Scand 7 Gastroenterol 1989; 24: 796-8.

13 Tallev NJ, Phillips SF. Non-ulcer dyspepsia: potential causes and pathophysiology. Ann Intern Med 1988; 108: 865-79.

14 Swarbrick ET, Hegarty JE, Bat I., William CB, Dawson AM

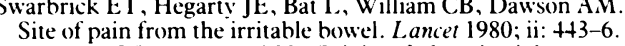
15 Kingham JGC, Dawson AM. Origin of chronic right upper quadrant pain. Gut 1985; 26: 783-8. 